\title{
SSC decision ends post-war era of science-government partnership
}

Washington. A physics community stunned by Congress's final decison to kill the Superconducting Super Collider (SSC) has been waking up to the realization that, both for its own discipline and for science in general, nothing will ever be quite the same again.

"This [decision] breaks the very successful partnership between science and government which has extended since the war. starting from the Manhattan Project", says Stan Wojcicki of Stanford University, chairman of the government's High Energy Physics Advisory Panel (HEPAP). "That partnership involved a level of mutual confidence which has now broken down."

Last Thursday, 21 October, Hazel O'Leary, the secretary of energy, issued a shock order terminating the $\$ 11$ billion Texan project - which is one-fifth complete following a decision by a joint committee of the Senate and House of Representatives to pull the plug.

The decision was taken after powerful supporters in the Senate, led by Bennett Johnston (Democrat, Louisiana), conceded to overwhelming opposition in the House, where critics had claimed that the project, however worthy, was unaffordable.

Some SSC supporters blamed the Clinton administration's half-hearted support for the project's collapse. Although the administration has supported the project in public, it is said to be privately relieved to watch it die, as it tries to shift spending on science from basic to applied research (see Nature 365, 195: 1993).

As the Internet communications network surged with tens of thousands of messages between anxious scientists whose work relates to the project, leading US high energy physicists were regrouping to ensure the survival of their discipline by going international - probably through greater participation in the proposed Large Hadron Collider (LHC) at CERN, the European Laboratory for Particle Physics.

"The only good thing to come out of this will be more international collaboration", says Sidney Drell, deputy director of the Stanford Linear Accelerator Center (SLAC) in California. Drell urges physicists to work for fully-fledged US and Japanese involvement to convert CERN from a European centre to an international one.

"It's important that we move forward while there is still some momentum on this frontier of research, and the LHC is the one machine that we know how to build", says Drell. "The most horrible thing would be if we just folded up the tent and went home."

George Brown (Democrat, California), who is chairman of the House Science Com- mittee, describes the decision as a "tragedy", and says that his committee will now seek to engage the White House's Office of Science and Technology Policy and O'Leary's Energy Department in a "serious

\section{IMAGE UNAVAILABLE FOR COPYRIGHT REASONS}

exploration" of future US involvement in fundamental physics.

"The only course I can see now is one of international collaboration, possibly on the CERN upgrade", says Brown. He adds that a formal affiliation to CERN would "not be a big step for us". CERN's charter currently excludes non-European countries from full membership, although 500 American and 110 Japanese physicists work at the facility, on the Swiss-French border, paid for by their respective universities.

But Wojcicki, who calls last Thursday "a very sad day for high energy physics and for our country", estimates that a useful US involvement in the LHC would mean spending at least $\$ 500-\$ 700$ million on a detector for the planned European accelerator.

$\mathrm{He}$ is deeply sceptical that such a sum would ever be approved by the US Congress "when we can't appropriate money for our own project". Wojcicki says he has considered resignation, but will stay to chair an HEPAP meeting in two weeks' time that will discuss how to respond to the termination of the discipline's dominant project.

Roy Schwitters, the director of the SSC, denies that recent allegations of mismanagement had been a decisive factor in the SSC's demise (see Nature 364, 92; 1993). "The essential line of attack was that curiosity-driven science is somehow frivolous, and a luxury we can no longer afford",

\section{CERN sees move as mixed blessing}

Munich. When Carlo Rubbia, head of the European Laboratory for Particle Physics (CERN) in Geneva, formally put forward his original plan to build the Large Hadron Collider (LHC) two years ago, the organization's 19 member states unanimously agreed that it was the right way forward for European high energy physics.

Washington's decision last week to stop construction of the equivalent US machine, the Superconducting Super Collider (SSC), may have shaken this confidence. But CERN physicists remain confident that the LHC will indeed be approved next spring, despite rumoured increases in cost.

The Rubbia plan anticipates that the LHC will absorb virtually all CERN's resources during its development, scheduled for completion in 2001. The total cost of the basic collider of between SFr2 and SFr3 billion (US\$1.4-\$2.1 billion) would come out of CERN's normal subscriptions; its two detectors, costing another SFr700 million, would be funded from other sources, in particular national science agencies.

According to supporters of the project, the steep bill is justified by the clear scientific aims of the project, including the detection of the predicted fundamental particle known as the Higgs boson.

Work on the design of the LHC and its detectors has been under way for some time.
Around 900 of the 6,000 scientists who visit CERN each year, and one-third of its 1,000 staff scientists, are already deeply involved in this part of the project.

Individual member states are beginning to firm up their commitment. Earlier this month, for example, the Dutch government became the first to commit funds for the construction of one of the detectors, announcing that it had agreed to provide SFr12.5 million for this purpose.

A detailed costing of the collider will be presented to the CERN council when it meets in December. But there could be a problem if, as seems likely, this costing exceeds Rubbia's original estimates. If it does, member countries may be asked to increase their normal CERN contributions to cover it.

Government will then have a few months to consider their options before a decision is made at a special CERN council meeting planned for next April. But with so many CERN countries looking for ways to save money in their research budgets - and elsewhere - the US decision could become an excuse for some to revise their views about Europe's financial (and scientific) priorities.

Hermann Strub, for example, head of Germany's delegation to CERN, says that lobby groups within the scientific 


\section{SSC: End of an era}

- he says. Schwitters says that his top priority for now is looking after the 2,000 staff at the SSC laboratory. "Everyone feels a sense of commitment to capturing what we have done", he says. Management at CERN and the SSC are already conferring on how the data can be captured and built upon.

The budget bill due to be passed by Congress this week includes $\$ 640$ million for termination costs at SSC in the coming year, the amount that was to have been spent continuing with the project. This money is supposed to cover restoration of the huge site to its previous state and 90 days' severance plus relocation expenses for the staff, as well as outstanding claims by hundreds of subcontractors.

But Brown says that, once legal settlements with the state of Texas and other likely litigants are included, two years of funding at that level will be needed to wind up the project. That will take the total cost of the debacle to more than $\$ 3$ billion. "It is very difficult for me to perceive why people in their right minds would pursue this course of action", says Brown.

Language in the budget bill requires O'Leary to prepare a report by next July on how to "maximize the value of the investment that has been made". Schwitters says his preliminary understanding is that land restoration will require only that tunnel entrances be closed and made safe, and not that the 15 miles of tunnel already dug be filled in again.

Scientific opponents of the collider were keeping a low profile after the decision. Philip Anderson, professor of particle physics at Princeton University, who has testified in Congress against the project, said he derived no satisfaction from its demise. He declined to comment further; "anything else I say now will be taken as gloating", he says.

But Jocelyn Hong, director of the Washington lobby group OOPS! (Organizations Opposed to the SSC), said the decision would benefit scientists on smaller projects in other disciplines, and noted the generosity of the SSC severance terms. "They get 90 days' money", she says. "No-one else gets that."

Colin Macilwain

\section{SSC: European reaction}

community are now certain to campaign for the money to be diverted away from the LHC towards other scientific ends. Others argue that the existence of the SSC made it easier to argue the case for the LHC as a European rival.

On the other hand, the SSC cancellation could also provide an additional impetus for Europe to complete a scientific investigation that is already agreed to be the next logical step for particle physics.

Frank Close, head of theoretical physics at the United Kingdom's Rutherford Laboratory, describes the LHC as now "the only

\section{Japan fears negative impact on domestic spending}

Tokyo. The decision by the US Congress to terminate funding for the Superconducting Super Collider (SSC) could have a negative impact on funding for science in Japan, including Japanese participation in the European Laboratory for Particle Physics (CERN).

Since 1990, the United States has been putting pressure on Japan to contribute about $\$ 1.5$ billion to the construction costs of the SSC, a move resented by government officials and scientists in Tokyo.

But the pressure has also helped to make science a political issue in Japan, and has drawn attention to deficiencies in the research system, and in particular the poor state of its universities. Indeed, some Japanese academics fear that cancellation of the SSC could kill attempts to expand the government's budget for science.

Cancellation of the SSC could have a negative impact on negotiations with CERN, says a physicist at Japan's National High Energy Physics Laboratory (KEK), as US pressure for SSC support might have created a new funding mechanism that could

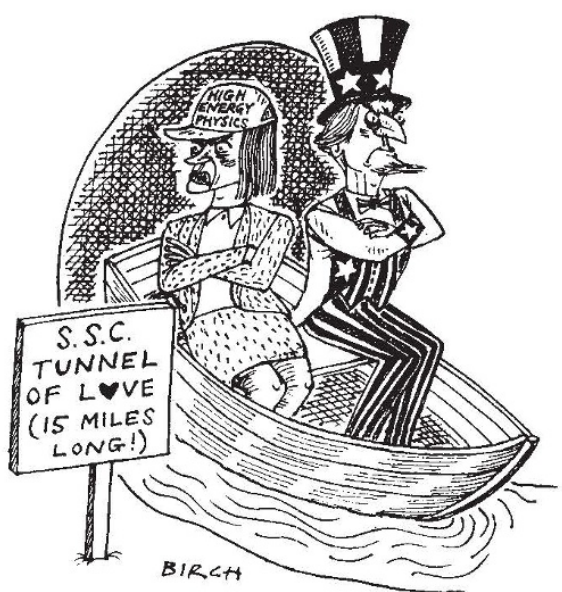

opportunity to access the first moments of the Universe". Furthermore, he says, reaching the scientific goals of the LHC will require achieving a number of significant technological breakthroughs, and this itself will produce numerous benefits.

Both CERN and its member countries are playing their cards close to their chests, unwilling to anticipate the extent of any overrun on the LHC's costs and reactions to it. One solution to both problems would be for the United States to enter a cooperative agreement with CERN, in other words to 'buy in' to the programme. Alison Abbott include a "small channel" to support Japanese participation in CERN. But not everyone shares this view; a university professor involved in CERN negotiations says it is not clear what effect the US decision will have.

But even if the SSC decision helps to clear the way for more decisive negotiations over CERN, there is no guarantee that the Japanese government will have any money to offer. "According to the newspapers many Japanese scientists are quite happy [about SSC decision]", says one science adviser to the Japanese government. "But I worry that it will have a bad effect on the expansion of budgets for basic science."

This adviser complains that Japanese politicians do not understand the difference between the SSC and other high-energy physics projects. As a result, he says, it may now become more difficult to win full funding for KEK's plans for a B-meson factory (see Nature 380, 330; 1993) let alone for CERN, because politicians and the Ministry of Finance are very reluctant to fund new projects in a time of recession.

Japanese supporters of the SSC are trying to make the best of last week's decision. "We are surprised and very disappointed", says Takahiko Kondo of KEK, leader of Japanese participation in the SSC, adding that Japan has "learned a lot" from participation in preparations for the SSC.

Funding from the US -Japan programme on high-energy physics has allowed Japanese scientists to conduct "risky research" that they were not able to do when building the TRISTAN electron-positron collider at KEK. As a result, they have developed new superconducting magnets and integrated circuits that will be patented, and will find uses elsewhere in high-energy physics.

Kondo predicts that international competition in B-meson physics will heat up as "US refugees" from the SSC turn to Bmeson physics. But he worries that European governments may "cool" their support of CERN and that this could have an adverse world-wide effect on high-energy physics.

David Swinbanks

\section{Mayor nominated for \\ second UNESCO term}

Paris. The executive board of the United Nations Educational, Scientific and Cultural Organisation (UNESCO) last week nominated Federico Mayor, the Spanish biochemist who is UNESCO's current director general, as its candidate for a second six-year term.

Mayor will be formally elected by the UNESCO general conference on 6 November. 